\title{
PV Generator Driven First Order Circuit - Transient Analysis using Lam- bertW Function
}

\author{
Sandeep Sharma* and Avinashi Kapoor*
}

Department of Electronic Science, University of Delhi, South Campus, Benito Juarez Marg, New Delhi - 110021 India

\begin{abstract}
The study of dynamic behaviour of circuits containing one or more energy-storing circuit elements powered by photovoltaic (PV) generator has been an intriguing aspect to the PV module design engineer. A PV module constitutes a special power source that has a transcendental current-voltage relationship. As can be expected this makes the transient response analysis for such circuits far more complicated than the conventional power source. Methods and models have been suggested to study the transient behaviour of such circuits. Earlier works on first order circuits have assumed that there are no current leakage losses in the form of Shunt resistance for a PV generator. In absence of an exact closed form solution for the transcendental current-voltage relations of a PV generator, these methods approximately describe the transient behaviour both quantitatively and qualitatively. Here we present an approach that uses exact closed form solutions based on Lambert W function, having incorporated finite value of shunt resistance for the PV generator.
\end{abstract}

Keywords: First order circuit analysis, Solar cell, Transient analysis, LambertW function, Photovoltaic generator.

\section{INTRODUCTION}

For higher efficiency of Photovoltaic (PV) systems it is very important for the designer to be able to have as accurate a value as possible for a) various design parameters, b) the load analysis of the PV generator for the given load as well as c) the transient analysis of the entire system. Specific case studies and analysis [1-6] have been formulated earlier by others. A generic study of the first order circuits with PV generator has been performed by Zacharias et al. [7].

Zacharias et al. [7] established that of the available methods incremental method is the best approach to solve the first-order non-linear differential equation. According to this method, the current $\mathrm{i}(\mathrm{t})$ will be calculated only for some discrete values of $t$. In particular, with the value of current $i_{N}$ known at $\mathrm{t}=\mathrm{NT}$, an equation $\mathrm{i}_{\mathrm{N}+1}$ relating to $\mathrm{i}_{\mathrm{N}}$. Such an equation is a special case of a difference equation, a technique for converting the governing non-linear differential equation into a linear differential equation in each time interval $\mathrm{T}$ and then into a difference equation.

However the PV generator (PVG) model considered by them does not account for current leakage losses in the form of Shunt resistance for the PVG, and their belief of nonexistence of an exact closed form solution to the transcendental current-voltage relation of a PVG. Exact closed form solution to solve the transcendental current-voltage relation of a PVG has been proposed by Jain et al. [8-11].

In this study to have a greater degree of accuracy we have based our solution on LambertW function incorporating

*Address correspondence to these authors at the Department of Electronic Science, University of Delhi, South Campus, Benito Juarez Marg, New Delhi - 110021 India;

E-mails: deep.arma@gmail.com, avinashi_kapoor@yahoo.com a finite shunt resistance thus overcoming the above inabilities. Incremental model has been used to analyze the transient behaviour of first order circuit.

\section{PV GENERATOR}

For an equivalent circuit representing a PVG appropriately it requires to take into account the presence of parasitic series resistance and shunt conductance's [12-14]. No model would be complete without the consideration of these losses. We here use the single diode exponential model that takes care of these losses in the form of a series and a shunt resistance connected to the diode and a source as shown in Fig. (1):

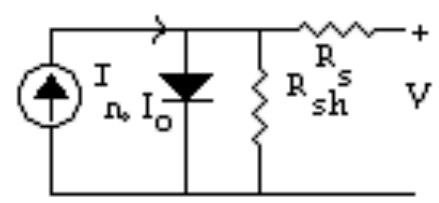

Fig. (1). Single diode exponential model for a Solar Cell.

This model mathematically can be expressed as

$$
i=I_{0}\left(\exp ^{\left(\frac{v-i R_{s}}{n V_{t h}}\right)}-1\right)+\frac{v-i R_{s}}{R_{s h}}-I_{p h}
$$

The above relation is a transcendental current-voltage relation. An exact closed form solution, based on LambertW function, to this equation is

$$
v=i\left(R_{s}+R_{s h}\right)+R_{s h}\left(I_{0}+I_{p h}\right)-n V_{t h} \text { Lambert } W\left(\frac{I_{0} R_{s h}}{n V_{t h}} \exp ^{\left(\frac{R_{s h}\left(i+I_{0}+I_{p h}\right)}{n V_{h t}}\right)}\right)
$$




$$
i=\frac{v-R_{s h}\left(I_{0}+I_{p h}\right)}{R_{s}+R_{s h}}+n V_{t h} \operatorname{Lambert} W\left(\frac{I_{0} R_{t} R_{s}}{n V_{t h}} \exp ^{\left(\frac{R_{t}\left(v+R_{s}\left(I_{0}+I_{p h}\right)\right)}{n V_{t h}}\right)}\right)
$$

where $R_{t}=R_{s h} /\left(R_{s}+R_{s h}\right)$ and other symbols have their usual meaning. The above expressions are valid for a single cell. In case of an array we need to have an expression that takes into account the current and voltages due to all the cells. PVG is a collection of interconnected solar cells and other components. It is assumed that the entire array is dealt as a system constituting $\mathrm{N}$ strings in parallel having $\mathrm{M}$ cells connected in series per string and all the cells are identical.

For a series array consisting of $\mathrm{M}$ identical cells where the current through the array is equal in each cell and the voltage be given as

$$
V_{a}\left(i_{a}\right)=\sum_{n=1}^{M} V_{n}\left(i_{a}\right)
$$

Considering these series strings in parallel to each other thus keeping the voltage across the array constant and the current through the array is equal to sum of currents through parallel strings.

$$
i_{a}(V)=\sum_{n=1}^{N} i_{n}(V)
$$

here $i_{n}$ is the total current passing through the string of $M$ cells connected in series as above. Now replacing various parameters as considered by Applebaum et al. [15] $\mathrm{R}_{\mathrm{s}}=$ $0.9 \Omega, \mathrm{I}_{\mathrm{o}}=0.0081 \mathrm{~A}, \mathrm{~V}_{\mathrm{th}}=0.0422 \mathrm{~V}^{-1}$ and $\mathrm{I}_{\mathrm{ph}}=13.615 \mathrm{~A}$ at an insolation of $1000 \mathrm{Wm}^{-2}$ in expressions as suggested by us earlier (Jain et al. [11]). Also the value of $\mathrm{R}_{\mathrm{sh}}$ is taken to be as $1000 \Omega$. The Array constitute has 324 cells connected in a series to form a string and 18 strings in parallel.

\subsection{PVG Connected to a Series RL Load}

The circuit equation using Kirchoffs Voltage Law for the circuit shown in Fig. (2a)

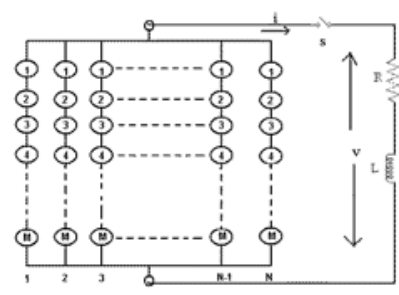

(a)

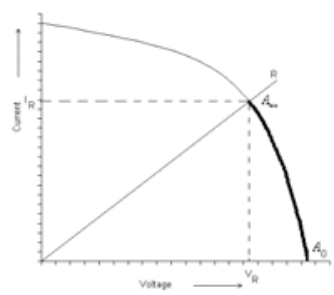

(b)
Fig. (2). PVG connected to a series RL Load (a) circuit diagram (b) dynamic route (heavy line) \& the linear model.

$$
L \frac{d i}{d t}+R i=v(i)
$$

therefore replacing $\mathrm{v}(\mathrm{i})$ from above we have

$$
L \frac{d i}{d t}+R i=\sum_{q=1}^{M} V_{q}\left(i_{a}\right)
$$

Applying the linear operator $\Delta$ to both sides of equation (6a) one gets

$$
L \frac{d(\Delta i)}{d t}+R \Delta i=\Delta v(i)
$$

where $\Delta \mathrm{i}=\mathrm{i}_{\mathrm{N}+1}-\mathrm{i}_{\mathrm{N}}$, for all $\mathrm{i}=\mathrm{i}_{\mathrm{N}+1}$ for $\mathrm{t}_{\mathrm{N}}<\mathrm{t}<\mathrm{t}_{\mathrm{N}}+\mathrm{T}$

$$
\text { and } \mathrm{i}=\mathrm{i}_{\mathrm{N}} \text { for } \mathrm{t}=\mathrm{t}_{\mathrm{N}}
$$

However by Taylor's expansion we get

$$
\Delta v(i)=\frac{d v(\Delta i)}{d i}+\delta \Delta i \quad \text { implying } \quad \Delta v(i)=\frac{d v(\Delta i)}{d i}
$$

defining $\mathrm{R}_{\mathrm{so}}=|\mathrm{dv} / \mathrm{di}|$ as the dynamic or incremental resistance of the PV element, then from eqn we get

$$
R_{s o}=\frac{R_{s}}{1-\frac{R_{t}}{1+\text { LambertW }\left(\frac{I_{0} R_{s} R_{t}}{n V_{t h}} e^{\left(\frac{R_{t}\left(v+R_{s}\left(I_{0}+I_{p h}\right)\right)}{n V_{t h}}\right)}\right)}}
$$

for our array

$$
\mathrm{R}_{\mathrm{sa}}=\mathrm{R}_{\mathrm{so}} * \mathrm{M} / \mathrm{N}
$$

Since $\mathrm{dv} / \mathrm{di}<0$ it follows that

$$
\frac{d v}{d i \mid i=i_{n}}=-R_{s a_{n}}
$$

therefore equation (9) can be written as

$$
\Delta v=-R_{s a_{n}}\left(i_{N+1}-i_{N}\right)
$$

Substituting equation (8) \& (11) equation (7) becomes

$$
L \frac{d i_{N+1}}{d t}+\left(R+R_{s a_{N}}\right) i_{N+1}=v_{N}+R_{s a_{N}} i_{N}
$$

This equation is valid for the interval $t_{N}<t<t_{N}+T$. The solution of this equation yields the current $i_{N+1}$ at $t=t_{N}+T$ as

$$
i_{N+1}=\frac{v_{N}+R_{s a_{N}}}{R+R_{s a_{N}}}+\left(i_{N}-\frac{v_{N}+R_{s a_{N}}}{R+R_{s a_{N}}}\right) e^{-B_{s a_{n}} T}
$$

where $v_{N}$ is calculated for $i=i_{N}$ from

$$
v=i\left(R_{s}-R_{s h}\right)+k+V_{o c} \text { Lambert } W\left(\frac{V_{o c}-R_{s h} I_{p h}}{V_{o c}\left(e^{\frac{V_{o c}}{n V_{t h}}}-1\right)} e^{\left.\frac{k}{V_{o c}}-i R_{s h}\right)}\right)
$$

where $k=\frac{V_{o c}-I_{p h} R_{s h} e^{\frac{V_{o c}}{n V_{t h}}}}{e^{\frac{V_{o c}}{n V_{t h}}}-1}$ and $B_{s a_{n}}=1 / \tau_{N}$

implying $B_{s a_{n}}=\left(R+R_{s a_{N}}\right) / L$ 
equation (13) is the desired difference equation and is recursive in nature.

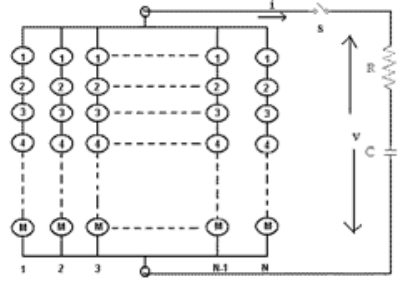

(a)

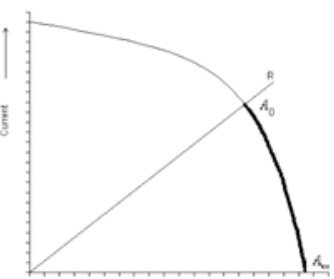

(b)
Fig. (3). PVG connected to a series RC Load (a) circuit diagram (b) dynamic route (heavy line) \& the linear model.

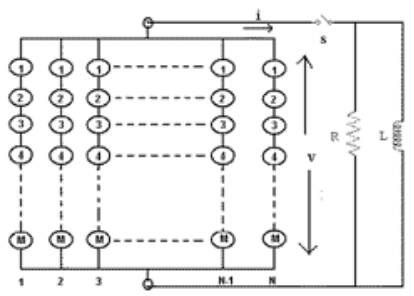

(a)

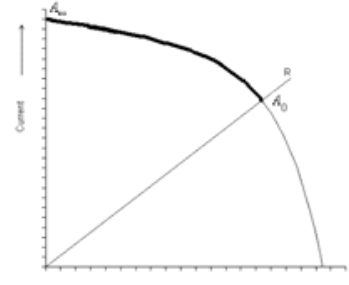

(b)
Fig. (4). PVG connected to a parallel RL Load (a) circuit diagram (b) dynamic route (heavy line) \& the linear model

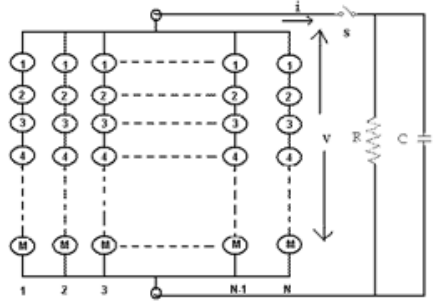

(a)

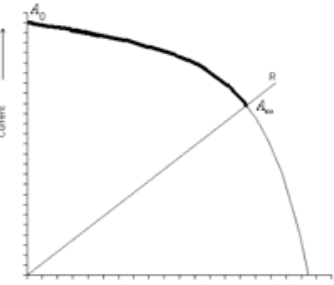

(b)
Fig. (5). PVG connected to a parallel RC Load (a) circuit diagram (b) dynamic route (heavy line) \& the linear model.

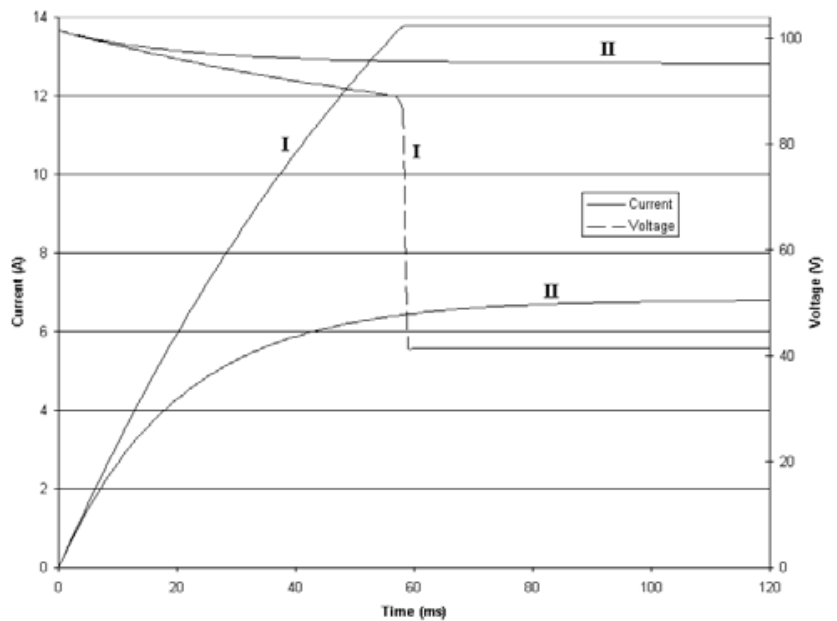

Fig. (6). PVG current \& voltage vs. time in a PV RL series circuit for (I) $\mathrm{R}=3 \Omega \& \mathrm{~L}=0.3 \mathrm{H}$ (II) $\mathrm{R}=14 \Omega \& \mathrm{~L}=0.3 \mathrm{H}$.

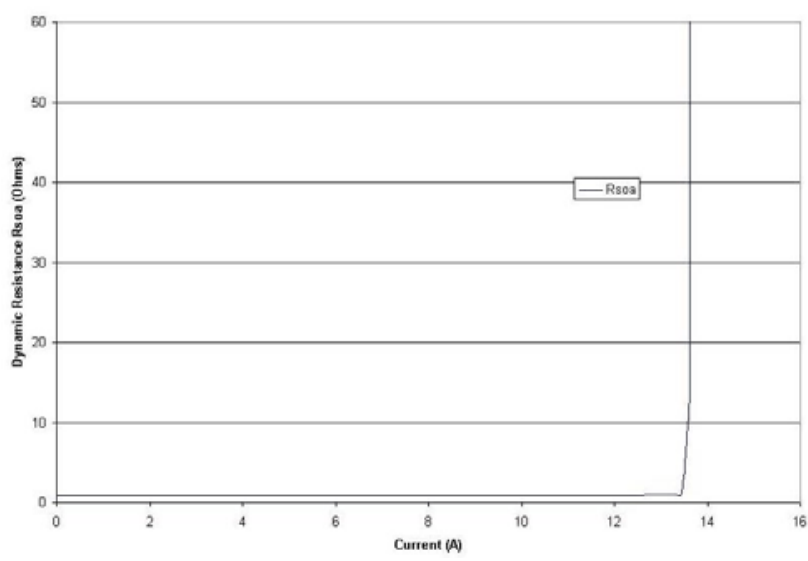

Fig. (7). Dynamic Resistance vs PV Generator current in a PV RL series circuit for $\mathrm{R}=3 \Omega \& \mathrm{~L}=0.3 \mathrm{H}$.

\subsection{PVG Connected to a Series RC Load}

The circuit equation using Kirchoffs Voltage Law for the circuit shown in Fig. (3):

$$
\frac{C\left(R+R_{s a_{N}}\right) d\left(\Delta v_{C N+1}\right)}{d t}+v_{C N+1}=v_{N}+R_{s a_{N}} i_{N}
$$

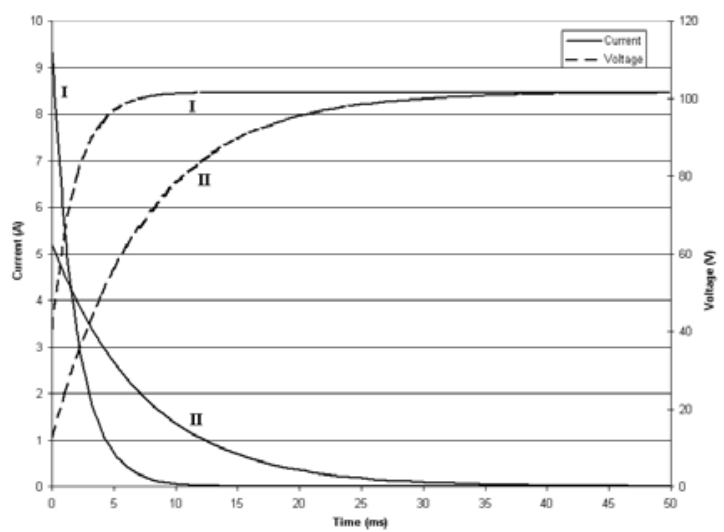

Fig. (8). PVG current \& voltage vs. time in a PV RC series circuit for (I) $\mathrm{R}=3 \Omega \& \mathrm{C}=500 \mu \mathrm{f}$ (II) $\mathrm{R}=14 \Omega \& \mathrm{C}=500 \mu \mathrm{f}$.

The solution for the capacitor voltage at $\mathrm{t}=\mathrm{t}_{\mathrm{N}}+\mathrm{T}$ is

$v_{C N+1}=v_{N}+R_{s a_{N}} i_{N}+\left(v_{C N}-v_{N}-R_{s a_{N}} i_{N}\right) e^{-B_{s a_{n}} T}$

where $B_{s a_{n}}=\frac{1}{C\left(R+R_{s a_{N}}\right)}$

the PVG current is given by

$$
i_{N+1}=\frac{v_{N}+R_{s a_{N}} i_{N}-v_{C N+1}}{R+R_{s a_{N}}}
$$

\subsection{PVG Connected to a Parallel RL Load}

The circuit equation using Kirchoffs Voltage Law for the circuit shown in Fig. (4a) 
$L\left(\frac{1}{R}+\frac{1}{R_{s a_{N}}}\right) \frac{d i_{L N+1}}{d t}+i_{L N+1}=\frac{v_{N}+R_{s a_{N}} i_{N}}{R_{s a_{N}}}$

leads to the solution for the inductor current $\mathrm{i}_{\mathrm{LN}+1}$ at $\mathrm{t}=\mathrm{t}_{\mathrm{N}}+\mathrm{T}$ is

$$
i_{L N+1}=\frac{v_{N}+R_{s a_{N}} i_{N}}{R_{s a_{N}}}+\left(i_{L N}-v_{N}-R_{s a_{N}} i_{N}\right) e^{-B_{s a_{n}} T}
$$

where $B_{s a_{n}}=\frac{R R_{s a_{N}}}{L\left(R+R_{s a_{N}}\right)}$

the PVG current is given by

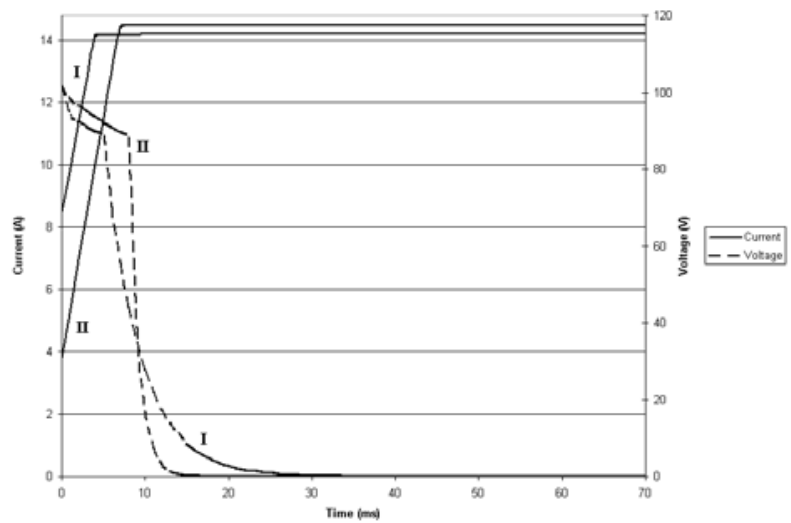

Fig. (9). PVG current \& voltage vs. time in a PV RL parallel circuit for (I) $\mathrm{R}=14 \Omega \& \mathrm{~L}=0.3 \mathrm{H}$ (II) $\mathrm{R}=50 \Omega \& \mathrm{~L}=0.3 \mathrm{H}$.

$$
i_{N+1}=\frac{v_{N}+R_{s a_{N}}\left(i_{N}+i_{L N+1}\right)}{R+R_{s a_{N}}}
$$

\subsection{PVG Connected to a Parallel RC Load}

The circuit equation using Kirchoffs Voltage Law for the circuit shown in Fig. (5).

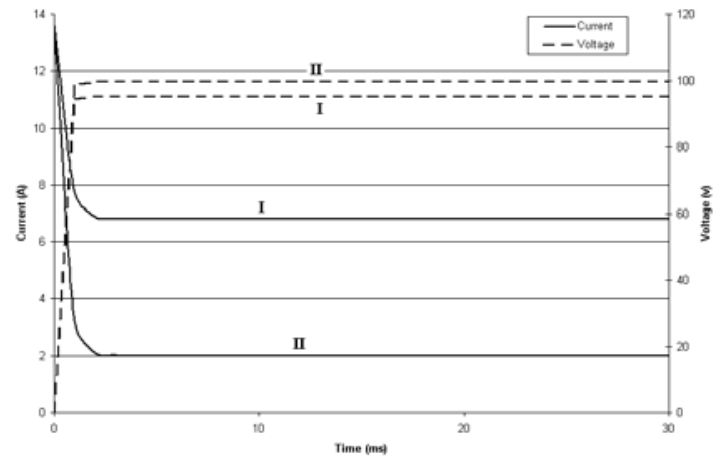

Fig. (10). PVG current \& voltage vs. time in a PV RC parallel circuit for (I) $R=14 \Omega \& C=500 \mu f$ (II) $R=50 \Omega \& C=500 \mu f$.

$$
\frac{C d v_{C N+1}}{d t}+v_{C N+1}\left(\frac{1}{R}+\frac{1}{R_{s a_{N}}}\right)=\frac{v_{N}+R_{s a_{N}} i_{N}}{R_{s a_{N}}}
$$

The solution for the capacitor voltage at $\mathrm{t}=\mathrm{t}_{\mathrm{N}}+\mathrm{T}$ is

$$
\begin{aligned}
& v_{C N+1}=\frac{R\left(v_{N}+R_{s a_{N}} i_{N}\right)}{R+R_{s a_{N}}}+\left(v_{C N}-\frac{R\left(v_{N}+R_{s a_{N}} i_{N}\right)}{R+R_{s a_{N}}}\right) e^{-B_{s a_{n}} T} \\
& \text { where } \quad B_{s a_{n}}=\frac{R+R_{s a_{N}}}{C R R_{s a_{N}}}
\end{aligned}
$$

the PVG current is given by

$$
i_{N+1}=\frac{v_{N}+R_{s a_{N}} i_{N}-v_{C N+1}}{R_{s a_{N}}}
$$

Table 1. Comparison of Results Between Zacharias et al. [7] (ZIM) and Using LambertW Function (LIM) for Solutions in the PV R-L Series Circuit for Different Time Steps $(R=3 \Omega, L=0.3 H)$

\begin{tabular}{|c|c|c|c|c|c|c|c|c|}
\hline Time $(\mathbf{m s})$ & \multicolumn{2}{|c|}{ Step Size $\mathbf{0 . 1} \mathbf{~ m s}$} & \multicolumn{2}{c|}{ Step Size = 1.0 ms } & \multicolumn{2}{c|}{ Step Size = 2.5 ms } & \multicolumn{2}{c|}{ Step Size = 5.0 ms } \\
\hline & $\mathbf{Z ~ I M}$ & $\mathbf{L I M}$ & $\mathbf{Z ~ I M}$ & $\mathbf{L I M}$ & $\mathbf{Z ~ I M}$ & LIM & Z IM & LIM \\
\hline \hline 5 & 2.7966 & 1.637843 & 2.7967 & 1.637843 & 2.7974 & 1.637844 & 2.7997 & 1.637845 \\
\hline 10 & 5.3226 & 3.172524 & 5.3229 & 3.172524 & 5.3244 & 3.172527 & 5.3295 & 3.172531 \\
\hline 15 & 7.5787 & 4.610524 & 7.5792 & 4.610528 & 7.5818 & 4.610535 & 7.5905 & 4.610545 \\
\hline 20 & 9.5572 & 5.957922 & 9.5581 & 5.957931 & 9.5622 & 5.957944 & 9.5760 & 5.957964 \\
\hline 25 & 11.2357 & 7.22041 & 11.2370 & 7.220424 & 11.2437 & 7.220446 & 11.2658 & 7.220479 \\
\hline 30 & 12.5579 & 8.403316 & 12.5604 & 8.403337 & 12.5723 & 8.40337 & 12.6103 & 8.403421 \\
\hline 35 & 13.3757 & 9.511628 & 13.3802 & 9.511659 & 13.4041 & 9.511708 & 13.4806 & 9.511782 \\
\hline 40 & 13.5388 & 10.55001 & 13.5392 & 10.55006 & 13.5407 & 10.55013 & 13.5559 & 10.55023 \\
\hline 45 & 13.5409 & 11.52282 & 13.5409 & 11.52289 & 13.5409 & 11.52299 & 13.5425 & 11.52314 \\
\hline 50 & 13.5409 & 12.4341 & 13.5409 & 12.43419 & 13.5409 & 12.43434 & 13.5409 & 12.43456 \\
\hline 55 & 13.5409 & 13.28747 & 13.5409 & 13.28763 & 13.5409 & 13.28787 & 13.5409 & 13.28822 \\
\hline 60 & 13.5409 & 13.63772 & 13.5409 & 13.77709 & 13.5409 & 13.70251 & 13.5409 & 14.08708 \\
\hline 65 & 13.5409 & 13.63772 & 13.5409 & 13.77709 & 13.5409 & 13.70251 & 13.5409 & 14.09541 \\
\hline
\end{tabular}




\section{CONCLUSION}

In this paper a comprehensive qualitative and quantitative analytical study of first order circuits powered by PVG module using incremental method incorporating LambertW function has been completed. Various graphs have been plotted to describe the circuit behavior for a PVG current \& voltage on a time line for: a RL series load circuit for (I) $R=3 \Omega \&$ $\mathrm{L}=0.3 \mathrm{H}$ (II) $\mathrm{R}=14 \Omega \& \mathrm{~L}=0.3 \mathrm{H}$ (Fig. 6). Dynamic Resistance vs PV Generator current in a RL series circuit for $\mathrm{R}=$ $3 \Omega \& \mathrm{~L}=0.3 \mathrm{H}$ (Fig. 7). RC series circuit for (I) $\mathrm{R}=3 \Omega \& \mathrm{C}$ $=500 \mu \mathrm{f}$ (II) $\mathrm{R}=14 \Omega \& \mathrm{C}=500 \mu \mathrm{f}$ (Fig. 8). RL parallel load circuit for (I) $\mathrm{R}=14 \Omega \& \mathrm{~L}=0.3 \mathrm{H}$ (II) $\mathrm{R}=50 \Omega \& \mathrm{~L}=0.3 \mathrm{H}$ (Fig. 9). RC parallel circuit for (I) $\mathrm{R}=14 \Omega \& \mathrm{C}=500 \mu \mathrm{f}$ (II) $\mathrm{R}=50 \Omega \& \mathrm{C}=500 \mu \mathrm{f}$ (Fig. 10). Results obtained by using incremental model without incorporating shunt Resistances as reported by Zacharias et al. [7] (Z I M) and incremental model using LambertW function (L I M) incorporating shunt resistance for solutions in the PV - R-L series circuit for different time steps $(\mathrm{R}=3 \Omega, \mathrm{L}=0.3 \mathrm{H})$ are tabulated in Table 1.

Thus from the above study it may affirm that $\mathrm{W}$ function technique incorporating a finite shunt and series resistance overcomes the known inabilities due to the absence of Shunt resistance in the PVG, and hence provides good correspondence to existing experimental results.

\section{REFERENCES}

[1] Applebaum, J. The operation of loads powered by separate sources or by a common source of solar cells. IEEE Trans. Energy Convers., 1989, 4(3), 351-357.

[2] Alghuwainem, S. M. Performance analysis of a PV powered DC motor driving a 3-phase self-excited induction generator. IEEE Trans. Energy Convers., 1996, 11(1), 155-161.
[3] Alghuwainem, S. M. Steady state performance of DC motors supplied from photovoltaic generators with a step-up converter. IEEE Trans. Energy Convers., 1992, EC 2, 267-272.

[4] Singer, S.; Applebaum, J. Starting characteristics of direct current motors powered by solar cells. IEEE Trans. Energy Convers., 1993, 8(1), 47-53.

[5] Fam, W. Z.; Balachander, M. K. Dynamic performance of a DC shunt motor connected to a photovoltaic array. IEEE Trans. Energy Convers., 1988, 3(3), 613-617.

[6] Saied, M. M. Matching of DC motors to photovoltaic generators for maximum daily gross mechanical energy. IEEE Trans. Energy Convers., 1988, 3(3), 465-471.

[7] Zacharias, T.H.; Milias-Argitis, J.; Makios, V. First-order circuits driven by a photovoltaic generator. Solar Cells, 1991, 31, 57-75.

[8] Jain, A.; Kapoor, A. Exact analytical solutions of the parameters of real solar cells using Lambert W-function. Solar Energy Mater. Solar Cells, 2004, 81, 269-277.

[9] Jain, A.; Kapoor, A. A new method to determine the diode ideality factor of real solar cell using Lambert W-function. Solar Energy Mater. Solar Cells, 2005, 85, 391-396.

[10] Jain, A.; Kapoor, A. A new approach to study organic solar cell using Lambert W-function. Solar Energy Mater. Solar Cells, 2005, 86, 197-205.

[11] Jain, A.; Sharma, S.; Kapoor, A. Solar cell array parameters using Lambert W-function. Solar Energy Mater. Solar Cells, 2005, 81, 25-31.

[12] Rajkanan, K; Shewchun, J. A better approach to the evaluation of the series resistance of solar cells. Solid State Electron., 1979, 22, 193-197.

[13] Oritz-Conde, A.; Garcia, F. J. Extraction of non-ideal junction model parameters from the explicit analytic solutions of its $I-V$ characteristics. Solid State Electron., 2005, 49(3), 465-472.

[14] Hovel, H. J. Solar Cells. In: Semiconductors \& Semimetals; Academic Press: New York, 1957; Vol. 11, p. 57.

[15] Applebaum, J. The quality of load matching in a direct-coupling photovotaic system. IEEE Trans. Energy Convers., 1987, EC-2, 534-541.

Received: February 17, 2009

Revised: April 13, 2009

Accepted: July 09, 2009

(C) Sharma and Kapoor; Licensee Bentham Open.

This is an open access article licensed under the terms of the Creative Commons Attribution Non-Commercial License (http://creativecommons.org/licenses/by-nc/3.0/) which permits unrestricted, non-commercial use, distribution and reproduction in any medium, provided the work is properly cited. 